\title{
Do eicosanoids cause colonic dysfunction in experimental $E$ coli 0157:H7 (EHEC) infection?
}

\author{
C J Bell, E J Elliott, J L Wallace, D M Redmond, J Payne, Z Li, E V O’Loughlin
}

Department of Gastroenterology, Royal North Shore Hospital, St Leonards, Australia

C J Bell

Department of Gastroenterology, The Royal Alexandra Hospital for Children, Westmead, Australia $\mathrm{Z} \mathrm{Li}$

E V O'Loughlin

Department of Paediatrics, University of Sydney, Sydney, Australia

E J Elliott

D M Redmond

J Payne

Intestinal Disease Research Unit, University of Calgary, Canada

J L Wallace

Correspondence to: Dr C Bell, Department of Gastroenterology, Royal

North Shore Hospital,

St Leonards, NSW, 2065, Australia. Email:

cbell@med.usyd.edu.au

Accepted for publication 21 December 1999

\begin{abstract}
Background-The pathophysiology of enterohaemorrhagic Escherichia coli (EHEC) infection remains unclear. Eicosanoids have been implicated as pathophysiological mediators in other colitides. Aims-To determine if prostaglandin $\mathbf{E}_{2}$ $\left(\mathrm{PGE}_{2}\right)$ and leukotriene $\mathrm{B}_{4}\left(\mathrm{LTB}_{4}\right)$ contribute to mucosal inflammation and dysfunction in EHEC colitis.

Methods-Ten day old rabbits were infected with EHEC. For five days after infection, mucosal synthesis of $\mathrm{PGE}_{2}$ and LTB $_{4}$ was measured in distal colonic tissue from control and infected animals and ${ }^{51} \mathrm{Cr}$-EDTA permeability was assessed in vivo. Myeloperoxidase activity was measured and histological inflammation and damage were assessed at five days in control and infected animals and after treatment of infected animals with the LTB $_{4}$ synthesis inhibitor MK-886. In separate experiments, ion transport was measured in Ussing chambers, before and after in vitro addition of the cyclooxygenase inhibitor indomethacin.

Results- LTB $_{4}$ synthesis was increased from day 2 after infection onwards and $\mathrm{PGE}_{2}$ synthesis was increased on day 3 . Mucosal permeability did not increase until day 5 after infection. MK-886 inhibited colonic $\mathrm{LTB}_{4}$ production but did not reduce diarrhoea, inflammation, or mucosal damage. Electrolyte transport was not significantly altered on day 3 after infection. However, both $\mathrm{Cl}$ secretion and reduced $\mathrm{Na}$ absorption found on day 5 were partially reversed by indomethacin. Conclusions-Tissue synthesis of $\mathbf{P G E}_{2}$ and LTB $_{4}$ did not correlate temporally with EHEC induced inflammation or changes in mucosal permeability and ion transport. Cyclooxygenase inhibition partially reversed ion transport abnormalities but lipoxygenase inhibition did not affect mucosal inflammation or histological damage. We conclude that the contribution of eicosanoids to mucosal injury and dysfunction is more complex than previously suggested.

(Gut 2000;46:806-812)
\end{abstract}

Keywords: enterohaemorrhagic; Escherichia coli; electrolyte transport; prostaglandins; leukotrienes; chloride secretion

Since their recognition as human pathogens in 1983, ${ }^{1}$ enterohaemorrhagic Escherichia coli (EHEC) have been found to be responsible for outbreaks and sporadic cases of diarrhoea, haemorrhagic colitis, and haemolytic-uraemic syndrome in North America, the UK, Japan, and Australia. ${ }^{2-5}$ We have previously demonstrated that EHEC infection of infant rabbits reproducibly results in diarrhoea, disruption of colonic electrolyte transport, and histological damage of the colonic mucosa. ${ }^{6}$ Sodium absorption is gradually abolished and chloride secretion develops abruptly five days after infection. ${ }^{7}$ However, the factors which mediate colonic dysfunction in EHEC infection remain largely unknown.

Supposed microbial virulence factors, such as shiga-like toxins, fimbrial adhesin, and the ability of the bacteria to produce attaching and effacing lesions, have not been convincingly implicated in the pathogenesis either by us ${ }^{7}$ or others. ${ }^{9}$ With regard to the contribution of host-defence factors to EHEC pathogenesis, we previously showed that neutrophils are important cellular mediators of structural and transport changes. ${ }^{7}$ In this study we used this well characterised model to test current paradigms for the pathophysiology of infectious colitis. ${ }^{10}$ Specifically, we wished to investigate the potential contribution of eicosanoid mediators to colonic inflammation, injury, and mucosal dysfunction in EHEC infection.

Eicosanoids have been proposed as important pathophysiological mediators in experimental colitis. ${ }^{10-14}$ Levels of both cyclooxygenase and lipoxygenase products are increased in inflamed colonic mucosa in human inflammatory bowel disease ${ }^{15}{ }^{16}$ and in animal models of colitis. ${ }^{17} 18$ Moreover, eicosanoids are recognised neutrophil products and have been linked to disruption of electrolyte transport ${ }^{101920}$ and to tissue injury. ${ }^{12} 1421$

Prostaglandin $\mathrm{E}_{2}\left(\mathrm{PGE}_{2}\right)$ has previously been demonstrated to be a potent and pivotal secretagogue in mammalian intestine. ${ }^{22}{ }^{23} \mathrm{PGE}_{2}$ itself stimulates chloride secretion ${ }^{19}$ and, in addition, mediates the secretagogue effects of other components of the inflammatory milieu. ${ }^{22}{ }^{24}$ Its role as an intestinal secretagogue has been convincingly demonstrated in monkeys infected with Salmonella ${ }^{25}$ and, more recently, in porcine cryptosporidiosis. ${ }^{11}$ It has also been suggested that $\mathrm{PGE}_{2}$ mediates the increased mucosal permeability induced by exposure of ileal loops to Clostridium difficile toxin $\mathrm{A} .{ }^{13}$

Abbreviations used in this paper: EHEC, enterohaemorrhagic Escherichia coli; $\mathrm{PGE}_{2}$, prostaglandin $\mathrm{E}_{2} ; \mathrm{LTB}_{4}$, leukotriene $\mathrm{B}_{4} ; \mathrm{Cr}$-EDTA, chromium-ethyldiaminetetraacetic acid; MPO, myeloperoxidase; PD, potential difference. 
Although some lipoxygenase products, such as 5-hydroxyeicosatetraenoic acid (5-HETE) and 5-hydroxperoxyeicosatetraenoic acid (5HPETE) also affect colonic electrolyte transport,${ }^{20}$ their predominant role in colitis is in the pathogenesis of mucosal inflammation and injury. ${ }^{14}{ }^{14326}$ Leukotriene $\mathrm{B}_{4}\left(\mathrm{LTB}_{4}\right)$, for example, is a potent chemotactic factor affecting leucocytes. ${ }^{27}$ Thus prostaglandins and leukotrienes have been incorporated into current concepts of the pathophysiology of infectious diarrhoea and assigned central roles. ${ }^{10}$

The aim of this study was to test these concepts by defining the role of eicosanoids in the pathophysiology of EHEC colitis in infant rabbits. We studied the temporal relationships between tissue $\mathrm{PGE}_{2}$ synthesis and ion transport changes and between mucosal $\mathrm{LTB}_{4}$ synthesis and tissue inflammation and damage. The contributions of $\mathrm{PGE}_{2}$ and $\mathrm{LTB}_{4}$ were further examined using inhibitors of eicosanoid synthesis. While cyclooxygenase products partially accounted for changes in ion transport, the results suggest a complex interplay among elements of the inflammatory milieu rather than any clear cut "cause and effect" role for either $\mathrm{PGE}_{2}$ or $\mathrm{LTB}_{4}$ in EHEC induced mucosal dysfunction.

\section{Methods}

ANIMAL MODEL

As previously described, litters of suckling 10 day old New Zealand white rabbits, free of diarrhoea, were inoculated intragastrically with $5 \times 10^{10} \mathrm{CFU}$ of EHEC strain EDL933 (serotype O157:H7, producing shiga-like toxins 1 and 2 and plasmid mediated fimbrial adhesin), suspended in $1 \mathrm{ml}$ of $10 \%$ sodium bicarbonate buffer. ${ }^{67}$ Control rabbits were inoculated with $1 \mathrm{ml}$ of bicarbonate buffer alone. Pups were kept with their mothers, who were allowed free access to chow and water. Animals were maintained on a 12 hour light/dark cycle. Pups were weighed daily and checked for perianal fur soiling to assess the development of diarrhoea. Infection was confirmed by plating rectal swabs onto sorbitol MacConkey agar and examining sorbitol negative colonies for the presence of O157 antigen by the slide agglutination method ( $E$ coli latex kit, Oxoid Ltd, Hampshire, UK). ${ }^{28}{ }^{29}$ The use and care of animals were approved by the animal ethics committee of the Children's Medical Research Institute.

\section{STUDY PROTOCOLS}

(1) To assess the time course correlations between mucosal eicosanoid levels and measures of mucosal inflammation, damage, and function, mucosal synthetic capacities for $\mathrm{PGE}_{2}$ and $\mathrm{LTB}_{4}$ were measured in control (uninfected) rabbits and in infected animals from day 1 to day 5 after inoculation.

(2) To assess the contribution of $\mathrm{LTB}_{4}$ to colonic inflammation and mucosal damage, infected animals were treated with intramuscular MK-886, an inhibitor of $\mathrm{LTB}_{4}$ synthesis. MK-886 blocks $\mathrm{LTB}_{4}$ production by inhibiting activation of 5-lipoxygenase through inhibition of en- zyme translocation. ${ }^{26}{ }^{30} \mathrm{MK}-886$, dissolved in $1 \%$ carboxymethylcellulose, was administered $(10 \mathrm{mg} / \mathrm{kg} /$ day $)$ two hours before infection and then daily for five days after infection. Body weight gain, severity of diarrhoea, distal colonic $\mathrm{LTB}_{4}$ synthesis, distal colonic myeloperoxidase (an index of mucosal inflammation), and histology score were measured five days after infection. Results were compared with data from control and infected animals not treated with MK-886. Vehicle treatment alone did not affect any measured parameter in infected animals (data from this group not shown).

(3) To assess the contribution of $\mathrm{PGE}_{2}$ to alterations in ion transport, distal colonic electrolyte transport was studied in vitro before and after addition of the cyclooxygenase inhibitor indomethacin in control animals and infected animals on days 3 and 5 after infection. The dose used (final concentration $10^{-6} \mathrm{M}$ dissolved in ethanol) completely abolished $\mathrm{PGE}_{2}$ release in this preparation. Pilot studies showed that the vehicle (ethanol, final concentration 1:100 vol:vol) did not significantly alter unidirectional or net ion fluxes or electrical parameters when added to day $3(n=5)$ or day 5 $(n=4)$ infected distal colon (data not shown). Indomethacin was added in vitro as it causes intestinal inflammation in vivo.

CLINICAL PARAMETERS, HISTOLOGY SCORE AND MYELOPEROXIDASE ACTIVITY

Clinical parameters were assessed in control (uninfected) rabbits and in infected rabbits 1-5 days after inoculation. Body weight gain (g) (over five days) was calculated from daily weight data. Severity of diarrhoea was scored according to the following criteria: 0 , no soiling; 1, slight soiling around the anus; 2, moderate soiling of the perineum; and 3, severe, covering the perineum and extending down both legs.

For histological assessment of mucosal inflammation and damage, segments of distal colon were removed, fixed in $4 \%$ buffered formalin, and blocked in paraffin. Sections were then stained with haematoxylin and eosin and examined by light microscopy by a single observer blinded to the experimental treatment. Scoring of colonic inflammation and mucosal damage is depicted in table 1 and is a modification of the schema reported by Rath and colleagues. ${ }^{31}$

Myeloperoxidase (MPO), an index of tissue neutrophil infiltration and inflammation, was measured as previously reported. ${ }^{7}$ Briefly, scraped mucosa from the distal colon was homogenised in hexadecyltrimethylammonium bromide buffer and sonicated for five seconds. Samples were snap frozen in liquid nitrogen and assayed within three days for MPO activity, as described by Krawisz and colleagues. ${ }^{32}$ Results are expressed as units per gram of mucosa. 
MUCOSAL EICOSANOID SYNTHETIC CAPACITY Mucosal synthetic capacity for $\mathrm{PGE}_{2}$ and $\mathrm{LTB}_{4}$ was assayed as previously described ${ }^{33}$ in control and infected animals from day 1 to day 5 after infection. Samples of distal colon (150-200 $\mathrm{mg}$ ) were placed in Eppendorf tubes containing $1.5 \mathrm{ml}$ of warmed $10 \mathrm{mM}$ sodium phosphate buffer, $\mathrm{pH}$ 7.4. After mincing with scissors for 15 seconds, samples were incubated at $37^{\circ} \mathrm{C}$ for 20 minutes in a shaking water bath and centrifuged at $1600 \mathrm{~g}$. The supernatant was stored at $-20^{\circ} \mathrm{C}$ and eicosanoid content was assayed within two weeks using commercial enzyme immunoassays (Cayman Chemical Co., Ann Arbor, Michigan, USA). After thawing, samples for $\mathrm{LTB}_{4}$ determination were centrifuged and boiled to degrade interfering substances ${ }^{34}$ prior to immunoassay. Measurement of colonic eicosanoid synthesis by this method has been shown previously to correlate well with measurements via in vivo rectal dialysis in an animal model of colitis. ${ }^{26}$

\section{MUCOSAL PERMEABILITY MEASUREMENT}

Permeability was assessed as a measure of mucosal function and as an additional index of mucosal damage. In vivo permeability to ${ }^{51} \mathrm{Cr}$ labelled ethylenediaminotetraacetic acid $\left({ }^{51} \mathrm{Cr}-\right.$ EDTA; DuPont) was studied in control rabbits and in day 2-5 EHEC infected rabbits using ligated colonic loops. In rabbits anaesthetised with intraperitoneal ketamine and xylazine, a carotid artery cannula was placed for blood sampling. The abdomen was opened and the renal pedicles were ligated. A cannula was placed in the proximal transverse colon and the colon distal to this was gently flushed with Krebs buffer warmed to $37^{\circ} \mathrm{C}$. After draining the colon of buffer, a distal colonic loop was formed by placing silk ligatures at the distal transverse colon and just above the rectum. Care was taken to avoid excessive handling of the colon and interruption of the vascular supply. The colon was kept moistened with saline during construction of the loop. After tying the distal ligature, $100 \mu \mathrm{Ci}$ of ${ }^{51} \mathrm{Cr}$-EDTA in $400 \mu \mathrm{l}$ of Krebs buffer were injected into the loop via polyethylene tubing introduced through the tightened proximal ligature. The tubing was then withdrawn as the ligature was tied. The abdomen was closed and the rabbit placed on a heating pad for the remainder of the study.

Some of the ${ }^{51} \mathrm{Cr}-\mathrm{EDTA} / \mathrm{Krebs}$ solution (50 $\mu \mathrm{l}$ ) was reserved for gamma counting (to estimate total activity of the instilled $400 \mu \mathrm{l}$ ) and arterial blood was drawn into heparinised syringes at 0 and 30 minutes. Blood samples were immediately centrifuged and $100 \mu \mathrm{l}$ plasma samples were set aside. After sample collection, the rabbit was killed and the length of the excised loop was measured. ${ }^{51} \mathrm{Cr}$ activities of the instilled buffer and the 30 minute plasma sample were subsequently determined by gamma spectrometry. Lumen to blood permeability was calculated as a percentage of the amount of ${ }^{51} \mathrm{Cr}$-EDTA instilled into the loop, which appeared per $\mathrm{ml}$ of plasma in 30 minutes, normalised to the length of the loop.

COLONIC ELECTROLYTE TRANSPORT STUDIES

Transport studies were performed on excised distal colon from control animals and EHEC infected rabbits three and five days after infection. Electrolyte transport was studied in vitro under voltage clamped steady state conditions as previously described. ${ }^{35}$ Animals were killed by cervical dislocation. The colon was immediately removed, opened along the mesenteric border, and gently washed of faeces. Two or three adjacent patches of unstripped colon from each rabbit were mounted in leucite Ussing chambers with exposed surface areas of $0.27 \mathrm{~cm}^{2}$. Each side of the tissue was bathed in Krebs/glucose buffer (containing (in $\mathrm{mmol} / \mathrm{l}$ ) $\mathrm{Na}^{+} 140, \mathrm{~K}^{+} 10, \mathrm{Mg}^{2+} 1.1, \mathrm{Ca}^{2+} 1.25, \mathrm{Cl}^{-} 127.7$, $\mathrm{HCO}_{3}{ }^{-} 25, \mathrm{H}_{2} \mathrm{PO}_{4}^{-} 2.0$, and glucose $10 ; \mathrm{pH}$ 7.4), maintained at $37^{\circ} \mathrm{C}$ by water jacketing of the glass reservoirs and oxygenated and circulated by means of a carbogen gas lift. Each side of the leucite chamber was connected via agar $/ \mathrm{KCl}$ bridges to voltage electrodes and to an automatic voltage clamp apparatus (DVC 1000, World Precision Instruments, New Haven, Conneticutt, USA). ${ }^{22} \mathrm{Na}$ and ${ }^{36} \mathrm{Cl}$ (5 $\mu \mathrm{Ci}$ ) were added to either the mucosal or serosal chamber to allow unidirectional flux calculations. After equilibration for 30 minutes, basal period short circuit current (Isc, in $\mu \mathrm{Eq} / \mathrm{cm}^{2} / \mathrm{h}$ ), potential difference (PD, in $\mathrm{mV}$ ), conductance ( $\mathrm{G}$, in $\mathrm{mSiemens} / \mathrm{cm}^{2}$ ), and steady state unidirectional fluxes $(\mathrm{J}$, in $\mu \mathrm{Eq} / \mathrm{cm}^{2} / \mathrm{h}$ ) of $\mathrm{Na}$ and $\mathrm{Cl}$ were measured during three consecutive 10 minute periods. Indomethacin was then added to both sides of the tissue and, after 35 minutes of further equilibration, electrical and flux measures were repeated. Tissue pairs were discarded if conductance differed by more than $25 \%$.

STATISTICAL ANALYSIS

Data are expressed as mean (SEM). Comparisons between data obtained at different times (that is, eicosanoid levels, distal colonic transport parameters, and permeability values) were performed by analysis of variance with subsequent multiple comparisons using Fisher's

Table 1 Histology damage score

\begin{tabular}{|c|c|c|c|c|}
\hline \multirow[b]{2}{*}{ Criteria } & \multicolumn{4}{|l|}{ Score } \\
\hline & 0 & 1 & 2 & 3 \\
\hline Histology & No damage & $\begin{array}{l}\text { Slight depletion of goblet cell } \\
\text { mucus; architecture and } \\
\text { epithelium intact; mild } \\
\text { apoptosis of surface colonocytes } \\
\text { (scattered cells). }\end{array}$ & $\begin{array}{l}\text { Majority of goblet cells depleted } \\
\text { of mucus; moderate apoptosis } \\
\text { (clusters of apoptotic bodies). }\end{array}$ & $\begin{array}{l}\text { All goblet cells depleted of } \\
\text { mucus; apoptotic cells } \\
\text { throughout epithelium; } \\
\text { microscopic ulceration of } \\
\text { surface epithelium }\end{array}$ \\
\hline PMN per high power field & None & $<10$ & $10-30$ & $>30$ \\
\hline Mucosal thickness $(\mu \mathrm{m})$ & Control thickness & $<25 \%$ thicker than control & $25-50 \%$ thicker than control & $>50 \%$ thicker than control \\
\hline
\end{tabular}



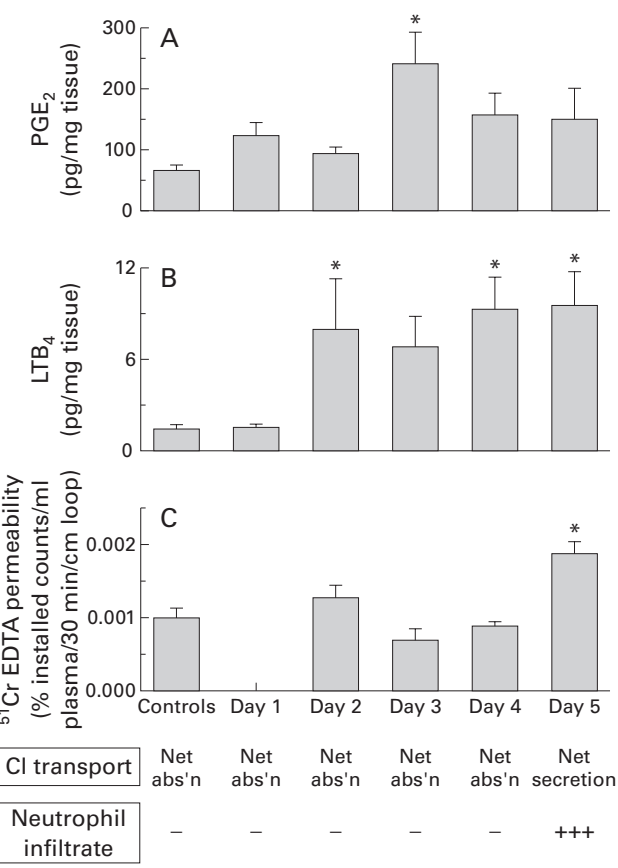

Figure 1 (A) Distal colonic mucosal PGE synthetic capacity in uninfected control rabbits and in EHEC

infected rabbits 1-5 days after inoculation. Data are mean (SEM), $n=12$ per group. ${ }^{\star} p<0.05$ compared with control, day 1 infected, and day 2 infected values. (B) Distal colonic mucosal $\mathrm{LTB}_{4}$ synthetic capacity in uninfected control rabbits and in EHEC infected rabbits 1-5 days after inoculation. Data are mean (SEM), $n=12$ per group. ${ }^{\star} p<0.05$ compared with control and day 1 infected values. (C) Distal colonic mucosal ${ }^{51} \mathrm{Cr}$-EDTA permeability in uninfected control rabbits and in EHEC infected rabbits 2-5 days after inoculation. Data are mean (SEM), $n=4$ per group. ${ }^{\star} p<0.05$ compared with control and other infected values. Lower panels show Cl transport and infiltration of the mucosa by neutrophils. Abs'n, absorption.

PLSD test. Electrolyte flux data before and after addition of indomethacin were compared by paired $t$ testing to determine the impact of indomethacin on colonic transport. $\mathrm{p}$ values $<0.05$ were regarded as significant.

\section{Results}

ANIMAL MODEL, CLINICAL PARAMETERS, AND HISTOLOGY

The majority of rabbits excreted EHEC O157:H7 in the stool by day 3 of infection and developed diarrhoea by day 5 . Animals did not lose weight and no animal died. Light microscopic appearances of day 3 infected colon were not different to control samples. Day 5 infected colon exhibited obvious inflammatory changes with infiltration of the lamina propria by neutrophils, necrosis of surface colonocytes, and occasional areas of mucosal ulceration. These histological features have been reported previously by us. ${ }^{67}$

Table 2 Clinical and mucosal parameters in control animals, in EHEC infected animals,

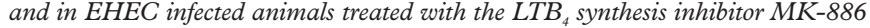

\begin{tabular}{lccc}
\hline & Control & Infected & Infected $+M K-886$ \\
\hline Weight gain (g) & $66(5)$ & $59(8)$ & $34(5)^{\mathrm{a}}$ \\
Diarrhoea score & 0 & $2.0(0.3)^{\mathrm{a}}$ & $2.7(0.1)^{\mathrm{a}}$ \\
LTB $_{4}$ (pg/mg mucosa) & $3.2(0.7)$ & $8.4(1.4)^{\mathrm{a}}$ & $2.0(0.4)^{\mathrm{ab}}$ \\
MPO activity (U/g mucosa) & $2.9(0.7)$ & $33.9(3.5)^{\mathrm{a}}$ & $36.6(7.4)^{\mathrm{a}}$ \\
Histology score & $0.3(0.1)$ & $5.4(0.3)^{\mathrm{a}}$ & $5.3(0.3)^{\mathrm{a}}$ \\
\hline
\end{tabular}

Data are mean (SEM) of $n=9-24$

${ }^{\mathrm{a}} \mathrm{p}<0.05$ compared with control; ${ }^{\mathrm{b}} \mathrm{p}<0.05$ compared with infected group.

$\mathrm{MPO}$, myeloperoxidase.
MUCOSAL EICOSANOID SYNTHESIS

Mucosal synthetic capacity for $\mathrm{PGE}_{2}$ was significantly higher in day 3 infected colon than in control colon or day 1 or day 2 infected tissue (fig 1A). Mean $\mathrm{PGE}_{2}$ levels remained high on days 4 and 5 after infection but were not significantly different from control values (using ANOVA with post hoc testing). Mucosal $\mathrm{LTB}_{4}$ synthetic capacity was significantly elevated on days 2,4 , and 5 after infection relative to values in control and day 1 infected colon (fig 1B).

\section{MUCOSAL PERMEABILITY}

In vivo distal colonic ${ }^{51} \mathrm{Cr}$-EDTA permeability was studied as an additional index of mucosal damage and as a measure of mucosal function. There were no changes in paracellular permeability until day 5 after infection (fig 1C). In day 5 infected rabbits, colonic ${ }^{51} \mathrm{Cr}$-EDTA permeability was significantly increased, being $60-100 \%$ higher than levels in control and other infected animals. The increase in mucosal permeability did not correlate with the time course of changes in $\mathrm{PGE}_{2}$ or $\mathrm{LTB}_{4}$ levels (fig 1) but corresponded temporally with the development of histological damage, onset of $\mathrm{Cl}$ secretion, and infiltration of the mucosa by neutrophils (fig 1, lower panels, as reported previously by us in this model).

COLONIC INFLAMMATION: EFFECT OF INHIBITION OF $\mathrm{LTB}_{4}$ SYNTHESIS

As expected, MK-886 treatment inhibited tissue synthesis of $\mathrm{LTB}_{4}$ (table 2). Infected rabbits treated with MK-886 gained significantly less weight over five days than control animals (table 2). However, MK-886 did not prevent the development of diarrhoea in infected animals. MK-886 treatment did not diminish the significant increases in mucosal MPO activity and histological damage and inflammation induced by EHEC infection (table 2).

\section{COLONIC ELECTROLYTE TRANSPORT: EFFECT OF} INHIBITION OF PGE $_{2}$ SYNTHESIS

Electrolyte transport was measured in distal colonic tissue from control rabbits and from infected animals three and five days after infection (table 3). Under basal conditions, control distal colon actively absorbed $\mathrm{Na}$ and, at a lower rate, Cl. PD and Isc values were high, consistent with predominantly electrogenic $\mathrm{Na}$ absorption. ${ }^{35}$ In day 3 infected tissue, flux values and electrical parameters were not significantly different from controls with the exception of the serosal to mucosal $(s \rightarrow m) \mathrm{Cl}$ flux, which was slightly but significantly lower.

By day 5 after inoculation with EHEC, $\mathrm{Na}$ absorption was markedly reduced and electrogenic $\mathrm{Cl}$ secretion was evident. $\mathrm{Na}$ absorption was virtually abolished due to a significant decrease in $\mathrm{JNa}_{\mathrm{m} \rightarrow \mathrm{s}}$ and a significant increase in $\mathrm{JNa}_{\mathrm{s} \rightarrow \mathrm{m}}$ compared with control and day 3 infected values. Net $\mathrm{Cl}$ transport was reversed from a low rate of absorption to net secretion due to a significantly lower $\mathrm{JCl}_{\mathrm{m} \rightarrow \mathrm{s}}$ flux. Despite these differences in electrolyte fluxes in day 5 infected colon, PD and Isc were no different to control values due to the concomitant reduc- 
Table 3 Effect of indomethacin on distal colonic electrolyte transport in control, and day 3 and day 5 EHEC infected rabbits

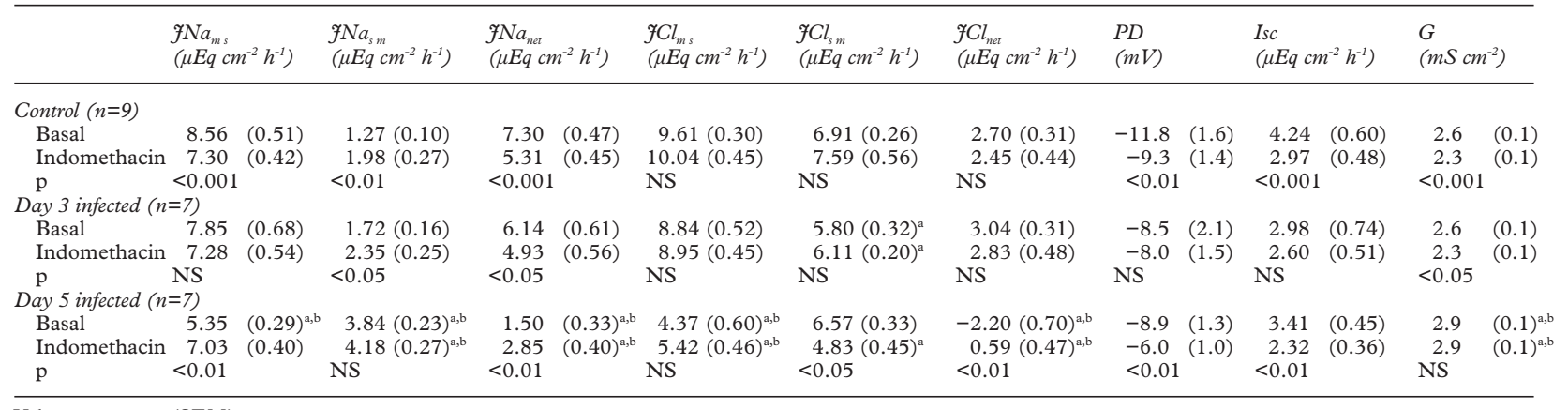

Values are mean (SEM)

$\mathrm{p}$, comparison between basal and indomethacin values using the paired $t$ test; NS, not significant.

$\mathrm{PD}$, potential difference; Isc, short-circuit current; G, conductance; $\mathrm{J}_{\mathrm{m} \rightarrow \mathrm{s}}$, mucosal to serosal flux; $\mathrm{J}_{\mathrm{s} \rightarrow \mathrm{m}}$, serosal to mucosal flux.

${ }^{\mathrm{a}} \mathrm{p}<0.05$ compared with control value for corresponding period; ${ }^{\mathrm{b}} \mathrm{p}<0.05$ compared with day 3 infected value for corresponding period.

tion in electrogenic $\mathrm{Na}$ absorption and development of electrogenic $\mathrm{Cl}$ secretion. ${ }^{6}$

Addition of indomethacin to the control distal colon caused a significant decrease in net $\mathrm{Na}$ absorption without any effect on $\mathrm{Cl}$ transport. The reduction in net $\mathrm{Na}$ absorption was due to a combination of significantly decreased $\mathrm{JNa}_{\mathrm{m} \rightarrow \mathrm{s}}$ and increased $\mathrm{JNa}_{\mathrm{s} \rightarrow \mathrm{m}}$. Control tissue PD, Isc, and $\mathrm{G}$ were significantly reduced after exposure to indomethacin. Indomethacin had little impact on transport across day 3 infected tissue. It caused a small but significant decrease in net $\mathrm{Na}$ absorption as a result of an increase in $\mathrm{JNa}_{\mathrm{s} \rightarrow \mathrm{m}}$ but did not affect $\mathrm{Cl}$ transport, PD, or Isc. In contrast, addition of indomethacin to day 5 infected tissue caused changes in both $\mathrm{Na}$ and $\mathrm{Cl}$ transport, significantly enhancing $\mathrm{Na}$ absorption and reversing $\mathrm{Cl}$ secretion to net absorption. The indomethacin induced increase in $\mathrm{Na}$ absorption was due to a significant increase in $\mathrm{JNa}_{\mathrm{m} \rightarrow \mathrm{s}}$ above basal period values. Net $\mathrm{Cl}$ secretion was reversed to a low level of absorption after addition of indomethacin due to a significant fall in $\mathrm{JCl}_{\mathrm{s} \rightarrow \mathrm{m}}$. Indomethacin also produced significant reductions in both PD and Isc in the day 5 infected group, consistent with impairment of an electrogenic ion transport process, most likely $\mathrm{Cl}$ secretion. However, indomethacin did not restore absorption of either $\mathrm{Na}$ or $\mathrm{Cl}$ to normal, with net fluxes of both electrolytes remaining significantly below control levels. After addition of indomethacin, net $\mathrm{Na}$ absorption remained lower in day 5 infected tissue than in control tissue because indomethacin had no effect on $\mathrm{JNa}_{\mathrm{s} \rightarrow \mathrm{m}}$ which remained significantly higher than the corresponding control value.

\section{Discussion}

The aim of this study was to test current concepts on the pathophysiology of infectious colitis by assessing the roles of $\mathrm{PGE}_{2}$ and $\mathrm{LTB}_{4}$ in a reproducible well characterised animal model. This also allowed us to further clarify the pathophysiology of EHEC colitis in infant rabbits and extend our previous time course observations in this model. We have reported in the past that inoculation of suckling rabbits with $E$ coli $\mathrm{O} 157: \mathrm{H} 7$ results in colonisation of the colon, mucosal inflammation, and diarrhoea. $^{67}$ Chloride secretion develops on day 5 after inoculation while $\mathrm{Na}$ absorption is gradually impaired and eventually abolished. ${ }^{7}$ Histological injury, inflammation, and neutrophil infiltration also occur abruptly on day 5 , coinciding with the onset of $\mathrm{Cl}$ secretion. A monoclonal antibody, which blocks neutrophil adhesion and emigration, prevents both the transport alterations and the histological damage, suggesting a pivotal role for neutrophils in the pathophysiology of EHEC infection. ${ }^{7}$

A growing body of evidence suggests that eicosanoids contribute significantly to the pathogenesis of colitis. Indeed, an important secretagogue role has been ascribed to $\mathrm{PGE}_{2}$ in current paradigms of the pathogenesis of infectious colitis. ${ }^{102336}$ Available evidence also suggests that $\mathrm{LTB}_{4}$ is a significant contributor to tissue inflammation and injury in experimental colitis. ${ }^{12} 142126$ The current study assessed the roles of $\mathrm{LTB}_{4}$ and $\mathrm{PGE}_{2}$ in producing these end points in EHEC colitis. The results question the contribution of these eicosanoids in this model.

In the current study, $\mathrm{LTB}_{4}$ levels increased markedly by day 2 after infection and remained high at later times. The levels did not correlate with the onset of mucosal inflammation (assessed histologically), damage (assessed by histology or by measurement of permeability), or neutrophil infiltration. Furthermore, successful inhibition of tissue $\mathrm{LTB}_{4}$ synthesis with MK-886 failed to attenuate diarrhoea, mucosal neutrophil infiltration, or histological inflammation and damage. (That the increase in $\mathrm{LTB}_{4}$ synthesis failed to correlate with the development of ion transport changes was not surprising as $\mathrm{LTB}_{4}$ has been shown not to affect colonic electrolyte transport. ${ }^{20}$ )

Closer correlations between the time courses of these parameters and $\mathrm{LTB}_{4}$ levels might have been expected given the reported effects of $\mathrm{LTB}_{4}$ on intestinal permeability ${ }^{21}$ and neutrophil chemotaxis ${ }^{27}$ and studies demonstrating that $\mathrm{LTB}_{4}$ perpetuates tissue inflammation, injury, and ulceration in colitis. ${ }^{12} 142126$ In trinitrobenzenesulphonic acid induced colitis, inhibitors of $\mathrm{LTB}_{4}$ synthesis promoted healing of ulcerated mucosa and reduced the severity of inflammation and damage when administered before induction of colitis. ${ }^{12-26}$ Of note, however, are other reports that inhibition of $\mathrm{LTB}_{4}$ synthesis does not attenuate human ulcerative 
colitis. ${ }^{37}$ Presumably, enhanced synthesis of $\mathrm{LTB}_{4}$ on day 2 in the current study, occurring well before demonstrable tissue neutrophil infiltration (day 5), arises from other cells capable of leukotriene production, such as lamina propria fibroblasts or resident, rather than newly recruited, leucocytes. Resident neutrophils have been shown in another model of gut injury to contribute to mucosal dysfunction. $^{38}$ Failure of elevated mucosal $\mathrm{LTB}_{4}$ levels to promptly attract neutrophils to the EHEC infected colonic mucosa suggests that other chemotactic factors may be responsible later in the evolution of the infection. Alternatively, some "permissive" factor or mediator, such as adhesion molecule expression on endothelial cells, may be absent until day 5 after EHEC inoculation when neutrophils eventually migrate into the colitic mucosa. ${ }^{7}$

Mucosal $\mathrm{PGE}_{2}$ levels also did not correlate well with changes in electrolyte transport. As $\mathrm{PGE}_{2}$ is a major paracrine regulator of fluid and electrolyte secretion in the colon, ${ }^{22}{ }^{23}$ we anticipated that increases in mucosal $\mathrm{PGE}_{2}$ synthesis would be parallelled by the onset of $\mathrm{Cl}$ secretion and diminished $\mathrm{Na}$ absorption. Mucosal PGE 2 synthetic capacity increased significantly by day 3 after infection but there were no changes in electrolyte transport at this time. By day 5, $\mathrm{Cl}$ secretion and impaired $\mathrm{Na}$ absorption were observed but indomethacin treatment only partially restored these abnormalities. The day 5 data (before and after indomethacin addition) would be consistent with the reported effects of exogenous $\mathrm{PGE}_{2}$ on colonic transport. ${ }^{19}{ }^{22}$ The partial restoration of electrolyte absorption by indomethacin suggests that $\mathrm{PGE}_{2}$ or other cyclooxygenase products play some part in disrupting both $\mathrm{Na}$ and $\mathrm{Cl}$ transport in EHEC colitis. However, the lack of transport abnormalities on day 3 and the incomplete effect of indomethacin in reversing the day 5 changes suggest that additional factors contribute to transport disruption. For example, EHEC induced damage to absorptive surface epithelial colonocytes might account for failure of indomethacin to completely restore day 5 net $\mathrm{Na}$ and $\mathrm{Cl}$ absorption to control levels.

There are various possible explanations for these temporal discrepancies between changes in $\mathrm{PGE}_{2}$ levels and transport. Pro-absorptive inflammatory mediators, such as $\mathrm{PGD}_{2}$, interleukin-10, or some neurotransmitters, might counteract the secretagogue effect of $\mathrm{PGE}_{2}$ at day $3{ }^{39-41}$ Synergism with another secretagogue might be necessary for the elevated levels of $\mathrm{PGE}_{2}$ to stimulate secretion, although numerous studies showing that $\mathrm{PGE}_{2}$ alone causes colonic $\mathrm{Cl}$ secretion make this a less likely explanation. Given our earlier finding that blockade of leucocyte adhesion and emigration prevented disruption of transport, ${ }^{7}$ we had wondered if neutrophil derived 5'-AMP ${ }^{42}$ might account for the abrupt onset of $\mathrm{Cl}$ secretion at day 5 . Other possible explanations include alterations in the mucosal neurosecretory apparatus, ${ }^{43}$ alterations in prostaglandin $\mathrm{E}$ receptor subtype profile, and hyporesponsiveness of the inflamed colonic epithelium (as we and others have demonstrated in experimental colitis). ${ }^{3343}$ Furthermore, we have recently demonstrated that within 18 hours of infection, EHEC renders T84 cells insensitive to $\mathrm{Cl}$ secretagogue stimulation. $^{8}$

Thus our results strongly suggest that the contribution of cyclooxygenase products to transport disruption is not as straightforward in EHEC colitis as in other experimental gut infections. ${ }^{11} 1325$ This may be because of different experimental designs. In the cryptosporidiosis study mentioned above ${ }^{11}$ for example, transport and tissue $\mathrm{PGE}_{2}$ levels were measured in control tissue and at one time point after infection. Had we measured $\mathrm{PGE}_{2}$ synthesis and transport only in control and day 5 infected animals, then similar conclusions about the role of $\mathrm{PGE}_{2}$ might have been reached as $\mathrm{PGE}_{2}$ levels were substantially increased on day 5 ( $\mathrm{p}=0.05$ by unpaired $t$ testing, day 5 infected $v$ control) and addition of indomethacin reversed transport changes, at least partially.

In conclusion, the present study provides further information on the pathophysiology of EHEC infection. Synthesis of eicosanoids is enhanced in the colonic mucosa of infected animals. While $\mathrm{PGE}_{2}$ or other cycloxygenase products appear to account for at least some of the colonic transport abnormalities, the temporal relationship between increased mucosal $\mathrm{PGE}_{2}$ and $\mathrm{Cl}$ secretion is not as straightforward as previously assumed. Moreover, $\mathrm{LTB}_{4}$ did not appear to play a major role in mucosal inflammation and injury. Thus for both cyclooxygenase and lipoxygenase products, the current data imply a complicated interplay of factors in the pathogenesis of mucosal inflammation and electrolyte transport abnormalities during EHEC infection. This complexity may be an important means by which host-defence mechanisms, such as intestinal secretion in response to luminal bacteria, are first upregulated and later switched off after elimination of the microbe.

The financial support of the National Health and Medical Research Council of Australia, the Children's Hospital Fund, the University of Sydney and QBE Insurance Ltd is gratefully acknowledged. MK-886 was generously provided by Dr A W Ford-Hutchinson of Merck Frosst Canada Inc.

1 Riley LW, Remis RS, Helgerson SD, et al. Hemorrhagic colitis associated with a rare Escherichia coli serotype. NEngl colitis associated with a rare

2 Pai CH, Gordon R, Sims HV, et al. Sporadic cases of haemorrhagic colitis associated with Escherichia coli O157:H7: clinical, epidemiologic, and bacteriologic features. Ann Intern Med 1984;101:738-42

3 Smith HR, Rowe B, Gross RJ, et al. Haemorrhagic colitis and vero-cytotoxin-producing Escherichia coli in England and Wales. Lancet 1987;i:1062-5.

4 Carter AO, Borczyk AA, Carlson JA, et al. A severe outbreak of Escherichia coli O157:H7 associated haemorrhagic colitis in a nursing home. N Engl f Med 1987;317:1496-500.

5 Cameron S, Walker C, Beers M, et al. Enterohaemorrhagic Escherichia coli outbreak in South Australia associated with the consumption of mettwurst. Comm Dis Intell 1995;19: $70-1$.

$6 \mathrm{Li}$ Z, Bell C, Buret A, et al. The effect of enterohaemorrhagic Escherichia coli $\mathrm{O} 157: \mathrm{H} 7$ on intestinal structure and solute transport in rabbits. Gastroenterology 1993;104:46774 . 
7 Elliott E, Li Z, Bell C, et al. Modulation of host response to Escherichia coli $\mathrm{O} 157: \mathrm{H} 7$ infection by anti-CD18 antibody in rabbits. Gastroenterology 1994:106:1554-61.

$8 \mathrm{Li} \mathrm{Z}$, Elliott E, Payne J, et al. Shiga toxin-producing Escherichia coli can impair T84 cell structure and function without inducing attaching/effacing lesions. Infect Immun 1999;67:5938-45.

9 Tzipori S, Karch H, Wachsmuth KI, et al. The role of a 60-megadalton plasmid and Shiga like toxins in the pathogenesis of infection caused by enterohaemorrhagic Escherichia coli $\mathrm{O} 157: \mathrm{H} 7$ in gnotobiotic piglets. Infect Immun 1987;55:3117-25.

10 Powell DW. New paradigms for the pathophysiology of infectious diarrhoea, Gastroenterology 1994;106:1705-7.

11 Argenzio RA, Lecce J, Powell DW. Prostanoids inhibit intestinal $\mathrm{NaCl}$ absorption in experimental porcine cryptosporidiosis. Gastroenterolog y 1993;104:440-7.

12 Wallace JL, MacNaughton WK, Morris GP, et al. Inhibition of leukotriene synthesis markedly accelerates healing in a rat model of inflammatory bowel disease. Gastroenterology 1989;96:29-36.

13 Triadafilopoulos G, Pothoulakis C, Weiss R, et al. Comparative study of Clostridium difficile toxin A and cholera toxin in (1989:97:1186-92.

14 Zipser RD, Nast CC, Lee M, et al. In vivo production of leukotriene $\mathrm{B}_{4}$ and leukotriene $\mathrm{C}_{4}$ in rabbit colitis: relationship to inflammation. Gastroenterology 1987;92:33-9.

15 Harris AW, Smith PR, Swan CHI. Determination of prostaglandin synthetase activity in rectal biopsy material and its significance in colonic disease. Gut 1978;19:875-7.

16 Sharon P, Stenson WF. Enhanced synthesis of leukotriene $\mathrm{B}_{4}$ by colonic mucosa in inflammatory bowel disease. Gastroenterology 1984;86:453-60.

17 Norris AA, Lewis AJ, Zeitlin IJ. Changes in colonic tissue levels of inflammatory mediators in a guinea-pig model of immune colitis. Agents Actions Suppl 1982;12:243-6.

18 Sharon P, Stenson WF. Metabolism of arachidonic acid in acetic acid colitis in rats: similarity to human inflammatory acetic acid colitis in rats: similarity to human in

19 Milton-Thompson GJ, Cummings JH, Newman A, et al. Colonic and small intestinal response to intravenous Colonic and small intestinal response to intrav
prostaglandin $\mathrm{F}_{2}$ and $\mathrm{E}_{2}$ in man. Gut 1975;16:42-6.

20 Musch MW, Miller RJ, Field M, et al. Stimulation of colonic secretion by lipoxygenase metabolites of arachidonic acid. Science 1982;217:1255-6.

21 Mion F, Cuber J-C, Minaire Y, et al. Short term effects of indomethacin on rat small intestinal permeability. Role of eicosanoids and platelet activating factor. Gut 1994 35:490-5.

22 Binder HJ, Sandle GI. Electrolyte absorption and secretion in the mammalian colon. In: Johnson LR, ed. Physiology of the gastrointestinal tract, vol 2, 2nd edn. New York: Raven, 1987:1389-418.

23 Powell DW. Immunophysiology of intestinal electrolyte transport. In: Field M, Frizzell RA, eds. Handbook of physiology. Intestinal absorption and secretion, vol IV. Bethesda, ology. Intestinal absorption and secretion, vol IV. Bethesc

24 Hanglow AC, Bienenstock J, Perdue MH. Effects of platelet-activating factor on ion transport in isolated rat platelet-activating factor on ion transport

25 Giannella RA, Rout WR, Formal SB. Effect of indomethacin on intestinal water transport in salmonella-infected acin on intestinal water transport in salmon
rhesus monkeys. Infect Immun 1977;17:136-9.

26 Wallace JL, Keenan CM. An orally active inhibitor of leukotriene synthesis accelerates healing in a rat model of colitis. Am f Physiol 1990;258:G527-34.
27 Ford-Hutchinson AW, Bray MA, Doig MV, et al. Leukotriene $\mathrm{B}_{4}$, a potent chemotactic and aggregating substance 266:264-5.

28 March SB, Ratnam S. Sorbitol MacConkey medium for detection of Escherichia coli O157:H7 associated with haemorrhagic colitis. F Clin Microbiol 1986;23:869-72.

29 March SB, Ratnam S. Latex agglutination test for detection of Escherichia coli serotype O157:H7. F Clin Microbiol 1989; 27:1675-7.

30 Gillard J, Ford-Hutchinson AW, Chan C, et al. L-663,536 (MK-886) (3-[1-(4-chlorobenzyl)-3-t-butyl-thio-5isopropylindol-2-yl]-2,2-dimethylpropanoic acid), a novel, orally active leukotriene biosynthesis inhibitor. Can $\mathcal{f}$ orally active leukotriene biosynthesi

31 Rath HC, Herfarth HH, Ikeda JS, et al. Normal luminal bacteria, especially bacteroides species, mediate chronic colitis, granulitis and arthritis in HLA-B27/human $\beta 2$ microglobulin transgenic rats. F Clin Invest 1996;98:94553.

32 Krawisz JE, Sharon P, Stenson WF. Quantitative assay for acute intestinal inflammation based on myeloperoxidase activity. Assessment of inflammation in rat and hamster models. Gastroenterology 1994;87:1344-50.

33 Bell CJ, Gall DG, Wallace JL. Disruption of colonic electrolyte transport in experimental colitis. Am $\mathcal{F}$ Physiol 1995;268:G622-30.

34 Peskar BM, Lange K, Hoppe U, et al. Ethanol stimulates formation of leukotriene $\mathrm{C}_{4}$ in rat gastric mucosa. Prostaglandins 1986;31:283-93.

35 O'Loughlin EV, Hunt DM, Kreutzmann D. Postnatal development of colonic electrolyte transport in rabbits. Am $\mathcal{F}$ Physiol 1990;258:G447-53.

36 Bern MJ, Sturbaum CW, Karayalcin SS, et al. Immune system control of rat and rabbit colonic electrolyte transport: role of prostaglandins and enteric nervous system. $7 \mathrm{Clin}$ Invest 1989;83:1810-20.

37 Roberts WG, Simon TJ, Berlin RG, et al. Leukotrienes in ulcerative colitis: results of a multicenter trial of a leukotriene biosynthesis inhibitor, MK-591. Gastroenterology 1997; 112:725-32.

38 Kubes P, Hunter J, Grainger DN. Ischemia/reperfusioninduced feline intestinal dysfunction: importance of granulocyte recruitment. Gastroenterology 1992;103:807-12.

39 Kashimura M, Okuno M, Himeno S, et al. Prostaglandin $\mathrm{D}_{2}$ diminishes transmural potential difference in rat colonic mucosa in vitro in contrast to the increasing effect of prostaglandin $\mathrm{E}_{1}$. Prostaglandins 1988;35:583-95.

40 Keenan CM, Rangachari PK. Eicosanoid interactions in the canine proximal colon. Am f Physiol 1989;256:G673-9.

41 Madsen KL, Tavernini MM, Mosmann TR, et al. Interleukin 10 modulates ion transport in rat small intestine. Gastroenterology 1996;111:936-44.

42 Madara JL, Patapoff TW, Gillece-Castro B, et al. 5'adenosine-monophosphate is the neutrophil derived para-
crine factor that elicits chloride secretion from $T_{84}$ intestinal epithelial monolayers. F Clin Invest 1993;91: intestinal

43 Goldhill JM, Burakoff R, Donovan V, et al. Defective modulation of colonic secretomotor neurons in a rabbit model of colitis. Am f Physiol 1993;264:G671-7.

44 MacNaughton WK, Leach KE, Prud'Homme-Lalonde L, et al. Ionizing radiation reduces neurally evoked electrolyte transport in rat ileum through a mast-cell dependent mechanism. Gastroenterology 1994;106:324-35. 